\title{
Uso da acerola como indicador ácido base alternativo
}

\author{
Daulton Ruan Rufino de Souza*; (Graduando em Química, Campus Currais Novos - IFRN) \\ Gesianny Crispim de Azevedo; (Graduanda em Química, Campus Currais Novos - IFRN) \\ Márcia Maria Fernandes Silva; (Docente em Química, Campus Currais Novos - IFRN) \\ *E-mail: daultonruan@gmail.com
}

Resumo:

É muito difícil conciliar o ensino de Química com o cotidiano dos alunos por falta de laboratórios e até mesmo por falta dos materiais. Com isso, este trabalho teve como objetivo analisar a acerola, já que ela tem uma cor forte (vermelha) decorrente da antocianina. Servindo como indicador ácido-base como material alternativo para aulas experimentais, facilitando o aprendizado do aluno e não sendo uma aula só teórica, mas sim, teórica e prática, tendo uma aprendizagem mais significativa.

Pallavras-chave: Ensino; indicador; ácido; base; acerola.

Espaço reservado para organização do congresso.

\section{Introdução}

A experimentação no ensino de Química tem sido defendida por diversos autores, pois constitui um recurso pedagógico importante que pode auxiliar na construção de conceitos no ensino de química (FERREIRA, HARTWIG, OLIVEIRA, 2010).

De acordo com Giordan (1999) a experimentação desperta no aluno interesse, independente do nível de escolarização, visto que tem um caráter motivador. Diante disso percebe-se a importância da motivação nas atividades experimentais, já que sem motivação o indivíduo se torna de certa forma incapaz de ampliar sua capacidade de aprendizado.

A proposta do experimento é importante no ensino e compreensão do método científico; o procedimento experimental pode aumentar a motivação dos alunos e ensinar-lhes as tarefas manipulativas e, a discussão dos resultados contribui para a aprendizagem dos conceitos científicos (Lôbo, 2011).

Na disciplina de Química no Ensino Médio, alguns assuntos atraem de forma mais significativa à atenção dos alunos. E onde se consegue notar esse aumento de interesse, é no estudo de ácidos e bases. Esse tema, além de abrir a imaginação do aluno, que ao ouvir a 
palavra “ácido" logo se lembra de cenas pitorescas de desenhos ou filmes de ficção, ainda abre as portas para o mundo da experimentação, visto que em muitas escolas esse é um dos poucos conteúdos cujo desenvolvimento o professor consegue dispor de material para realizar em sala (na maioria das vezes, apenas de forma demonstrativa), algum teste que permite ao aluno visualizar indicações do que antes ele apenas conhecia na teoria (BELLETTATO, 2012). Isso se evidencia mais ainda nas pequenas escolas do interior, onde a quantidade e a qualidade de informação não são suficientes para a formação de uma boa base.

Uma das maneiras usadas para detectar o ponto final de titulações baseia-se no uso da variação de cor de algumas substâncias chamadas indicadores. No caso particular das titulações ácido-base, os indicadores são ácidos ou bases orgânicas (fracos) que apresentam colorações diferentes, dependendo da forma que se encontra na solução (forma ácida ou básica) (BACCAN et al, 2001).

Sendo assim, a fruta utilizada foi à acerola servindo como indicador, já que a mesma possui cor vermelha, decorrente da presença de antocianinas. E que na perspectiva de Bobbio \& Bobbio (1995 apud Lima et al, 2002), “as antocianinas são pigmentos responsáveis por uma variedade de cores que variam do vermelho vivo ao violeta e azul. ”

E, de acordo com Bouillard (1982 apud Lima et al, 2003), "as antocianinas são pigmentos muito instáveis que podem ser degradadas, sob ação da vitamina C, oxigênio, temperatura, $\mathrm{pH}$ do meio, entre outros, no próprio tecido ou destruídas durante o processamento e estocagem dos alimentos. ”

Neste trabalho, optou-se por analisar esta fruta devido a existência de várias aceroleiras no Instituto Federal de Educação, Ciência e Tecnologia do Rio Grande do Norte Campus Currais Novos, tendo como objetivo utilizar a acerola como indicador ácido-base como material alternativo para que os alunos possam ter aulas teóricas e experimentais, facilitando assim um melhor desenvolvimento do aprendizado dos discentes.

\section{Metodologia}

Visando facilitar ao máximo a realização desse experimento, utilizou reagentes bastante simples e de baixas concentrações, como o ácido clorídrico e o hidróxido de sódio. Com tudo, para esse experimento eles podem ser facilmente substituídos por qualquer outro ácido e base que tenha disponível, até mesmos produtos do nosso dia-a-dia, como o vinagre e a soda cáustica. Assim essa prática pode ser utilizada até nas mais simples escolas do interior.

Para a extração do pigmento da acerola, pesou-se aproximadamente $16 \mathrm{~g}$ da fruta e adicionou-se $8 \mathrm{~mL}$ de álcool etílico comercial a $70 \%$ no liquidificador até triturar a fruta e em seguida foi filtrado. Deixou o extrato sob refrigeração e na ausência de luz por 24 horas afim de maximizar a quantidade de pigmento a extraído.

Para os testes do extrato de acerola como indicador, foram utilizados os seguintes reagentes para analisar a diferença de coloração entre os mesmos que tem valores de $\mathrm{pH}$ diferentes: Água sanitária, ácido clorídrico 0,1 mol/L, hidróxido de sódio 0,1 mol/L e detergente neutro. Colocaram-se as substâncias em quatro tubos de ensaios e em seguida acrescentou 5 gotas do extrato de acerola em cada tubo de ensaio, que foi agitado por 30 segundos até a mudança de coloração das substâncias analisadas.

\section{Resultados e Discussão}

Foram utilizados quatro reagentes de fácil obtenção para avaliar a possibilidade do extrato da acerola depois de passar 24 horas armazenadas sob refrigeração. Todas as análises foram realizadas em local escuro para não ter o risco de perder sua coloração, já que as antocianinas são fotossensíveis. 
Tabela 1: Discriminação das cores iniciais e finais em relação aos pHs.

\begin{tabular}{cccc}
\hline Reagentes & $\mathbf{p H}$ & Cor Inicial & Cor Final \\
\hline Água Sanitaria & 12,24 & Incolor & Incolor \\
\hline Ácido Cloridríco & 1,30 & Incolor & Avermelhado \\
\hline Hidroxido de Sódio & 13,10 & Incolor & Esverdiado \\
\hline Detergente Neutro & 8,05 & Amarelo & Alaranjado \\
\hline
\end{tabular}

Na Figura 1 observou-se o extrato natural da acerola. A partir das Figuras 2 e 3, percebeu-se que existe um mudança clara na coloração dos reagentes, indicando que o extrato pode ser usado como um indicador ácido-base. A Figura 2 mostra os reagentes sem o extrato, onde temos da esquerda para direita: Água sanitária, ácido cloridríco 0,1 mol/L, hidróxido de sódio 0,1mol/L e detergente neutro. Já a Figura 3 mostra os tubos com adição do extrato, que após a agitação mudaram perceptível de cor. Os reagentes tiveram seus pHs averiguados antes dos testes, os quais estão expressos na Tabela 1, que trás também as colorações iniciais e finais dos mesmos. No entanto, observou-se que a extração do indicador da acerola pode ser utilizado em aulas experimentais de escolas das redes públicas por serem de fácil obtenção e de baixo custo. Segundo Costa, Horton, Margolis e Chromatogr em 2000, as antocianinas são instáveis em pHs neutros ou alcalinos, explicando assim o porque de apenas em meio ácido houve uma mudança mais perceptível. Já a coloração esverdeada com o hidróxido de sódio possivelmente se deve a presença de clorofila no extrato.

Segundo o Macheix et al. (1990) apud Teixeira et al. (2008) o teor de antocianinas pode ser influenciado por diversos fatores, tais como, o clima, a temperatura e iluminação, que, dessa forma, dificultam a comparação entre diferentes cultivos de uma mesma fruta e flores. Isso faz com que cada fruto ou flor utilizado se comporte de maneira diferente, obtendo assim uma escala de coloração para cada extrato.

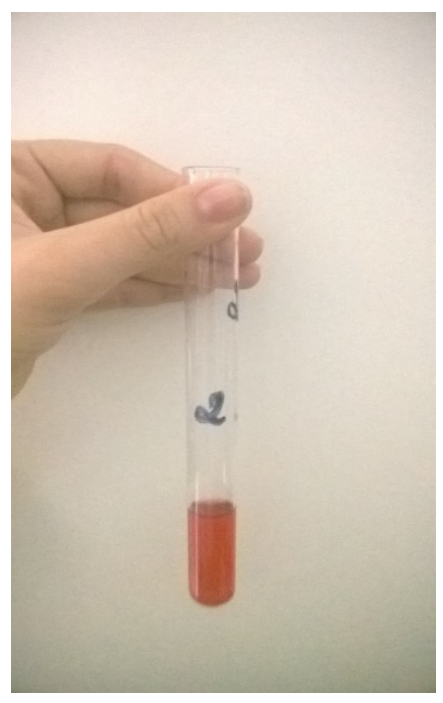

Figura 1: Extrato da acerola.

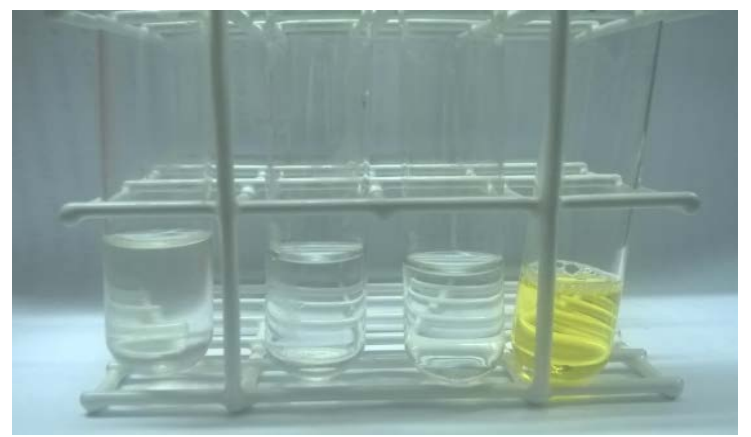

Figura 2: Reagentes antes da adição do extrato.

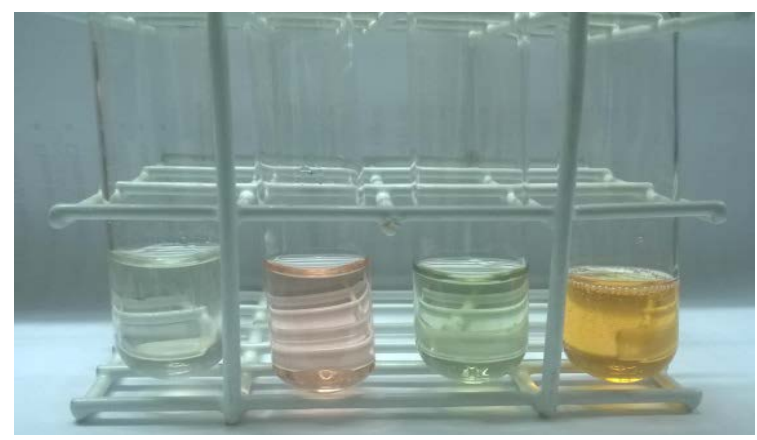

Figura 3: Reagentes após a adição do extrato. 


\section{Conclusão}

Nota-se a importância de usar a acerola como indicador ácido-base devido a sua forte coloração e por ser um componente bem acessível e barato, para futura utilização em aulas experimentais com os alunos do ensino médio, facilitando o aprendizado e fixando mais o conteúdo. O procedimento é relativamente simples porem atende bem o objetivo didático de diferenciar os ácidos de bases.

\section{Use of acerola as an indicator alternative acid base}

\section{Abstract:}

It is very difficult to reconcile the teaching of chemistry with the daily lives of students for lack of laboratories and even for lack of materials. Therefore, this study aimed to analyze the cherry, since it has a strong color (red) due to the anthocyanin. Serving as acid-base indicator as an alternative material for experimental classes, facilitating student learning and not being one lecture, but rather, theoretical and practical, with a more meaningful learning.

Keywords: Education; indicator; acid; base; acerola.

\section{Referências bibliográficas}

BELLETTATO, RAFAEL DONIZETE. Utilização de indicadores orgânicos de pH no ensino de ácidos e bases: considerando alguns aspectos históricos. In: XVI Encontro Nacional de a Ensino de Química. Vol 6. Salvador/BA, 2012. Disponível em: < http://www.portalseer.ufba.br/index.php/anaiseneq2012/article/view/7709/0>. Acesso em: 01 de Setembro de 2015.

BACCAN, N.; ANDRADE, J. C.; GODINHO, O. E. S.; BARONE, J. S.; Química Analítica Quantitativa Elementar, $3^{\text {a }}$ ed.; São Paulo: Edgard, Instituto Mauá de Tecnologia, 2001, p. 55.

COSTA, C. T.; HORTON, D.; MARGOLIS, S. A.; J. CHROMATOGR. A 2000, 881, 403.

FEREIRA, L.H., HARTWIG, D.R., OLIVEIRA, R.C., (2010) Ensino Experimental de Química: Uma Abordagem Investigativa Contextualizada. Química Nova na Escola. V.32, n.2, p.101.

GIORDAN, M., (1999) O papel da experimentação no ensino de ciências. Química Nova, n. 10, p. 43-49.

LÔBO, F., S., (2011) O trabalho experimental no ensino de química. Química Nova, v. 35, n. 2, p. 430-434.

TEIXEIRA, L. N.; STRINGHETA, P. C.; OLIVEIRA, F. A. de; Comparação de métodos para quantificação de antocianinas. Revistas Ceres, v. 55, n. 4, p. 297-304, 2008.

VERA LÚCIA ARROXELAS GALVÃO DE LIMA, ENAYDE DE ALMEIDA MÉLO, LUECI DOS SANTOS LIMA, DAISYVÂNGELA E. DA SILVA LIMA. Polpa congelada de acerola: efeito da temperatura sobre os teores de antocianinas e flavonóis totais. Rev. Bras. Frutic. Jaboticabal - SP, v. 24, n. 3, p. 669-670, Dezembro 2002. 
VERA LÚCIA ARROXELAS GALVÃO DE LIMA, ENAYDE DE ALMEIDA MÉLO, LUECI DOS SANTOS LIMA, DAISYVÂNGELA E. DA SILVA LIMA. Avaliação do teor de antocianinas em polpa de acerola congelada proveniente de frutos de 12 diferentes aceroleiras (malpighia emarginata d.c.). Ciênc. Tecnol. Aliment., Campinas, 23(1): 101-103, jan.-abr. 2003. 